\title{
An Evaluation of the Factors That Influences Caesarean Section in F.C.T Hospitals, Nigeria
}

\author{
Oyewole W.R; Umar A; Yayok R.P; Shinaba S.T; Atafo C.I; Olusanya M.O; \\ Department of Nursing Services, National Hospital Abuja-Nigeria.
}

\begin{abstract}
:
Introduction: Caesarean Section (CS) has been defined as delivery of a foetus through a surgical incision into the uterine wall after 28 weeks of gestation. Caesarean section has been seen and identified as a method of child delivery that is quicker, safer and more prestigious to the patient. The research reports on the factors that influenced Caesarean sections in the Tertiary Hospitals in Nigerian Federal Capital Territory. These factors amidst others are medical, social, physical, environmental and emergency.

Methods: Multi answered questions were asked various groups of respondents covering 8,040 consisting of the Obstetricians, Gynaecologist, Nurses and Patients. Simple tables, percentages, histograms, statistical analysis packages and pie charts were used for analyzing the data.

Results: The results show that the factors that influence Caesarean section are more of medical coupled with the choice of the patients for Caesarean section based on location, prestige, financial capability, facilities available at the centre, specialists available, safety, security and the confidentiality the patient has. In the evaluation, medical causes and emergency are ranked as the top most factors influencing Caesarean section. This is followed by prestige, age and late delivery. There are two types of Caesarean sections; namely emergency and elective CS with emergency CS ranked first.

Conclusions: Caesarean section even though quick, good and satisfactory, is not medically advisable as the first option for child delivery. Normal child delivery is encouraged if the patient's pelvis is matured. It is therefore recommended that there should be more education on general child delivery especially Caesarean sections.
\end{abstract}

Keywords: Caesarean Section, Obstetrics, Parity, Medical indications, Booked and Unbooked, Age

\section{Introduction}

Caesarean section is one of the oldest operations in surgery and one of the commonly performed surgical procedures in obstetrics dating back to 100 B.C. ${ }^{1}$ It is an essential operation that is used widely ${ }^{2}$. Caesarean section rates vary from one part of the country to another. USA has a rate of $20.3 \%$ recorded (Macfarlane \& Mug-ford, 1986). According to Broadhead and James (1995), a recorded rate of Caesarean sections around the World varies between $5 \%$ and $75 \%$. West African countries have a rate between $15 \%$ $21 \%^{4}$; while some teaching hospital in Nigeria has a rate range of about $18 \%-34.5 \%$ because they serve as referral centres to other hospitals $\mathrm{s}^{5,67,8}$. Studies from National Hospital in Nigeria place the rate at $22.6 \% 9$.

Caesarean section has been defined as delivery of a foetus through a surgical incision into the uterine wall after 28 weeks of gestation ${ }^{10}$. There are certain indications that call for Caesarean section which includesprevious Caesarean section, Cephalopelvic disproportion, foetal distress, failed induction, previous reconstructive vaginal surgery, abnormal presentation, multiple gestation, in excess of three and above , macrosomic baby, foetal abnormality, obstructive pelvic tumours, vulva herpes, retroviral diseases in PMTCT, several preeclampsia with unfavourable cervix, previous classical C/S., major placenta praevia. Others include retained second twin, bad obstetrics history, patient's request, primigravida, breech, prematurity, cord prolapsed, abruption with live foetus e.t.c ${ }^{1,5,11}$. Common complications include endometritis, haemorrhage, injury to internal organs and neonates, wound infection, wound adhessions, urinary tracts infection, D.V.T and in very rare cases maternal death which might be due to complications that necessitate operation or to the risk associated with surgery.

Jaiyesimi \& Ojo (2003) also identified the following factors that propelled the increasing rates of Caesarean section- difficult vaginal deliveries, unbooked status of most patients, improper function or absence of facilities like vacuum extractor, induction of electronic foetal monitoring leading to over diagnosis of foetal distress, societal demands for improved foetal outcome and aspirations of the obstetrician to meet their demands.

It has been estimated that 500 million women in developing countries are stunted as a result of malnutrition in childhood ${ }^{12}$. Many of these women have inadequate development of the bony pelvis, thus, increasing the risk of obstructed labour ${ }^{13}$. 
This study takes a cursory preview of the tertiary hospitals in Abuja to evaluate the factor(s) that influence the Caesarean section of their patients.

\section{Design and Study Area}

Survey design was used for the study. There are two tertiary hospitals in the Federal Capital Territory, Nigeria taken as the case study. They are National Hospital, Abuja and University of Abuja Teaching Hospital, Gwagwalada. They are taken so because they get referrals from other hospitals.

\section{Population}

The population covers the Doctors (Obstetricians and Gynaecologists), Nurses and Patients in these hospitals. The study therefore covers a total population of 8,040 consisting of Obstetricians and Gynaecologists (80), nurses (160) and Patients (about 7, 800) persons in a period of 2 years $(2011,2012$ ). The population is mainly those persons directly involved in Caesarean sections, both clinical staff and patients. This becomes necessary because of the delicate nature of information that is required for the research.

\section{Sampling and Sampling Technique}

The sampling techniques of random, multistage and stratified were adopted. The population was arrived at through a simple survey at random basis to get a total of 8,040 persons.

\section{Research Instruments}

Sample structure questionnaires consisting of about 10 multi-answered questions were partly used. Personal interview and contacts also help as instruments with medical records reflecting birth rate from the tertiary hospitals through Caesarean Sections were also used. They cover a period of two years thus, bringing a total population of about 8,040 , with an average population of 4,140 per annum. The researchers however take 8,080 as the population.

\section{Validity and Reliability}

The instruments and contacts were given to expert Obstetricians and Gynaecologists, nurses as well as patients that were literate enough to answer the questions. Raw data was also taken from the Obstetrics and Gynaecology department to ensure consistency and validity of instruments. Different classes of Caesarean Section based on age groups were also taken.

\section{Data Collection Procedures}

The primary data was collected through questionnaires and personal interviews from the population. There was special information on Caesarean Section from renowned Obstetricians ${ }^{14}$ and West African College of Surgeons Journal $2010^{15}$.

\section{Method of Data Analysis}

Data was analysed through sample percentages, tables, pie charts and descriptive cum-inferential statistical methods with the aid of statistical package for social science (SPSS). These methods were important because the research information were on the outcome of the survey more than establishing variables.

\section{Research Questions}

The following research questions were used to establish the factors that influenced Caesarean sections in the FCT.

a) What is the level of awareness of Caesarean section in F.C.T?

b) What are the indications for Caesarean sections?

c) What is the age of people with Caesarean sections in the study?

d) What are the factors and indices influencing Caesarean section in F.C.T?

e) How adequate is Caesarean section and how many types of Caesarean sections do you have?

\section{Results- Evaluation Of Research Questions}

\section{Question 1: What is the level of awareness of Caesarean Section in F.C.T?}

Federal Capital Territory (FCT) consists of 6 area councils namely- Abuja Municipal Area Council (AMAC); Bwari; Gwagwalada; Kuje; Kwali and Abuja. From present population survey and analysis, about fifty million people and above live in the F.C.T. Out of this figure; twenty million representing $20 \%$ are males, while thirty million representing $60 \%$ are females. The same survey shows that the population of females based on reproductive ages of between 16 yrs. and 50 yrs. are about 18 million representing $60 \%$ of the female population.

The tertiary hospitals as indicated elsewhere in this study are located in only two of the area council namely; 
a) AMAC with National Hospital and;

b) Gwagwalada with University of Abuja Teaching Hospital.

The level of awareness of Caesarean section based on the population of those that are literate is $10 \%$. The above is adduced to the fact that only those that are literate and attend antenatal clinics are mostly aware. The awareness is further reflected by the level of the number of patients that book for Caesarean section. The table 1 below shows the level of booking for ante-natal care.

Table 1 showing patients that registered for antenatal.

\begin{tabular}{|l|l|l|l|l|}
\hline S/N & Name of Tertiary Institution & Nos of Booked Patients & Nos of Unbooked Patients & Total \\
\hline 1 & National Hospital, Abuja & $1,268(48.81 \%)$ & $351(13.51 \%)$ & $1,619(62.32 \%)$ \\
\hline 2 & University of Abuja Teaching Hospital & $390(15.01 \%)$ & $589(22.67 \%)$ & $979(37.68 \%)$ \\
\hline & Total & $1,658(63.82 \%)$ & $940(36.18 \%)$ & 2,598 \\
\hline
\end{tabular}

Source: Delivery records from Tertiary Hospitals, 2011 - 2012.

The table above revealed that National Hospital located in the City Centre, Abuja, has the highest number of booked cases with $48.81 \%$ of total patients. This is attributed to literacy rate and location. Gwagwalada Teaching Hospital located at the suburb of the F.C.T has only $13.51 \%$ of the total patients booked and $22.67 \%$ of total patients as emergencies. The table concluded with $68.32 \%$ of patients booked while $36.18 \%$ are unbooked. From the table also, a pie chart can be drawn showing the booked and unbooked patients.

Table 2 showing the percentage of booked and unbooked cases

\begin{tabular}{|l|l|l|l|}
\hline S/N & Description & Number & Degrees $\left(^{\mathbf{0}}\right)$ \\
\hline 1 & Booked Patients & 1658 & 229.75 \\
\hline 2 & Unbooked Patients & 940 & 130.25 \\
\hline & & 2,598 & 360 \\
\hline
\end{tabular}

Figure 1 showing Booked and Unbooked Patients:

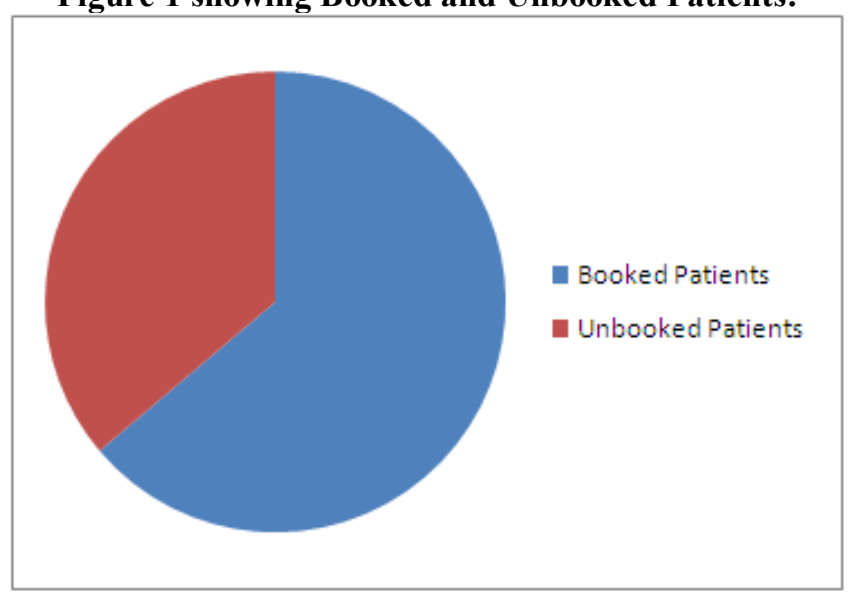

Question 2: What are the indications that call for Caesarean Section?

About 34 indications are identified as the causes for the Caesarean section performed in the Tertiary Institutions in the F.C.T. They could be classified into maternal, foetal or foetal maternal causes.

Table 3: Showing the indications for Caesarean Section in the Tertiary Hospitals in the F.C.T.

\begin{tabular}{|l|l|l|l|l|l|}
\hline S/N & Indication Characteristics & No of cases in UATH & \% & No of cases in NHA & \% \\
\hline 1 & Severe Oligohydraminous & 4 & 0.7 & 12 & 0.7 \\
\hline 2 & Poor progress & 42 & 4.0 & 71 & 4.3 \\
\hline 3 & Foetal distress & 142 & 14.5 & 140 & 8.6 \\
\hline 4 & Pre-eclampsia/ eclampsia & 160 & 16.3 & 164 & 10.1 \\
\hline 5 & Multiple gestation & 21 & 2.15 & 51 & 3.1 \\
\hline 6 & Metastatic CA & - & - & 1 & 0.06 \\
\hline 7 & Maternal request & 1 & 0.1 & 19 & 1.1 \\
\hline 8 & PMTCT & 4 & 0.4 & 127 & 7.8 \\
\hline 9 & Placenta praevia & 49 & 5.0 & 51 & 3.1 \\
\hline 10 & Abruptia placenta & 30 & 3.0 & 14 & 0.86 \\
\hline 11 & IVF pregnancy & 1 & 0.1 & 27 & 1.66 \\
\hline 12 & 2 previous C.S and above & 22 & 2.25 & 239 \\
\hline 13 & 1 previous C.S and other indications & 99 & 10.1 & 286 \\
\hline 14 & Breech presentation & 61 & 6.25 & 64 & 14.76 \\
\hline
\end{tabular}


An Evaluation of the Factors That Influences Caesarean Section in F.C.T Hospitals, Nigeria

\begin{tabular}{|l|l|l|l|l|l|}
\hline 15 & Macrosomia & 36 & 3.68 & 64 & 3.9 \\
\hline 16 & Bad Obstetric History(BOH) & 8 & 0.8 & 34 & 2.1 \\
\hline 17 & Obstructed labour & 215 & 22.0 & 72 & 4.4 \\
\hline 18 & Severe IUGR & 2 & 0.2 & 15 & 0.9 \\
\hline 19 & Congenital anomaly & 1 & 0.1 & 17 & 1.0 \\
\hline 20 & Previous myomectomy & - & - & 22 & 1.35 \\
\hline 21 & Ectopic kidney & - & - & 1 & 0.06 \\
\hline 22 & Fibroid in pregnancy & - & - & 12 & 0.74 \\
\hline 23 & Cord prolapsed & 10 & 1.02 & 7 & 0.43 \\
\hline 24 & Prom. Chorioamnionitis & 7 & 0.71 & 29 & 1.79 \\
\hline 25 & Malposition/ Malpresentation & 40 & 4.0 & 42 & 22 \\
\hline 26 & Failed IOL & 17 & 1.7 & 22 & - \\
\hline 27 & Genital warts & - & - & - & \\
\hline 28 & Status asthmaticus & - & - & 1 \\
\hline 29 & Cardiac disease & 1 & 0.1 & 2 & - \\
\hline 30 & IUFD & 6 & 0.61 & - & 0.06 \\
\hline 31 & Oedematous vulva & 1 & 0.1 & - & 0.12 \\
\hline 32 & Sickle Cell Disease (SCD) & - & - & 3 \\
\hline 33 & Paraplegia/ Pelvic injury & - & - & - & 5 \\
\hline 34 & Hand prolapsed & - & 4 \\
\hline
\end{tabular}

Source: Hospital records from NHA and UATH, 2011 and 2012

From the table 3 above, the indications as already classified are explained thus:

Maternal causes identified includes: previous section with other obstetric indication, two or more previous C.S, pre-eclampsia/ eclampsia, PMTCT, prolonged labour, bad obstetric history, failed induction, previous extensive, fibroid in pregnancy, IVF pregnancy, maternal request, Metastatic CA, previous vaginal surgery, bad obstetric history, cardiac disease, Oedematous vulva, SCD, e.t.c.

Foetal cases includes: foetal distress, breech presentation, placenta praevia, Macrosomia, multiple gestation, cord prolapse, hand prolapse, premature rupture of membrane (PROM) with Chorioamnionitis, congenital foetal anomaly.

Fetomaternal Causes includes: cephalopelvic disproportion, placenta praevia, primigravida breech, abruptio placenta, failed induction and delayed second stage.

However, from the above indications, there are differences in number of cases presented in the University of Abuja Teaching Hospital compared to National Hospital. It is observed that National Hospital has more of the following indications;

Pre-eclampsia (10.1\%); Multiple gestation (3.1\%); Maternal request (1.1\%); PMTCT (7.8\%); Placenta praevia (3.1\%); IVF pregnancy (1.66\%); Previous C.S (1, and 2 above- $17.6 \%$ and $14.76 \%$ respectively); Breech presentation (3.9\%); Macrosomia (3.9\%); BOH (2.1\%); Severe IUGR (0.9\%); Congenital anomaly $(1.0 \%)$; Previous myomectomy $(1.35 \%)$; Malpresentation $(2.59 \%)$ etc. The following reasons are adduced to the differences indicated above;

- There are more of booked cases in National Hospital,

- It is located more in the city centre,

- Literacy and awareness level.

However, in the University of Abuja Teaching Hospital, we have more of the following than National Hospital: Foetal distress (14.5\%); Pre-eclampsia (16.3\%); Placenta praevia (5.02\%); Abruptio placenta (3.0\%); Breech presentation (6.25\%); Obstructed labour (22.0\%); IUFD (0.1\%); which is due to the following reasons;

- They are mostly referral cases from Kwali, Abaji, Kubwa, Nyanya, etc.

- They have more of unregistered patients than National Hospital.

- The total number of patients is more in UATH than in the location.

- Because of the suburb nature of the hospital, they have more patients less than 18 years.

Question 3 what is the age range of patience with caesarean section as well as party?

The table 4 below is showing the age range of patience with C/S between year $2011 \& 2012$ of the case study.

\begin{tabular}{|l|l|l|l|l|l|}
\hline S/N & $\begin{array}{l}\text { AGE } \\
\text { RANGE(YEARS) }\end{array}$ & $\begin{array}{l}\text { PATIENTS IN } \\
\text { N.H.A }\end{array}$ & $\mathbf{\%}$ & $\begin{array}{l}\text { PATIENT } \\
\text { UATH }\end{array}$ & IN \\
\hline 1 & $1-18$ years & 4 & 0.2 & 27 & 2.1 \\
\hline 2 & $19-25$ years & 137 & 8.46 & 240 & 24.5 \\
\hline 3 & $26-30$ years & 487 & 30.0 & 381 & 39.0 \\
\hline 4 & $31-35$ years & 623 & 38.4 & 206 & 21.1 \\
\hline 5 & $36-40$ years & 326 & 20 & 94 & 9.6 \\
\hline 6 & 41-45 years & 39 & 2.4 & 16 & 1.6 \\
\hline 7 & 46-above & 3 & 0.18 & 2 & 0.2 \\
\hline
\end{tabular}




\section{Source: $O$ and G records, UATH \& NHA 2011 \&2012.}

From the Tertiary Institutions under study, Caesarean section cases are more in ages 26-30 years in UATH with 39\% while there are more in ages 31-35 years in NHA with 38.4\%, The reasons for this include; the patients at UATH are more from the suburb, more illiterates and they start child bearing more early than what obtains at National Hospital-where the patients are more sophisticated, centrally located and start child bearing late. This also explains why you have more of CS in age groups $41-46^{+}$in National Hospital than UATH.

The age distribution is pictorially shown in the bar chart below as figure 2 .

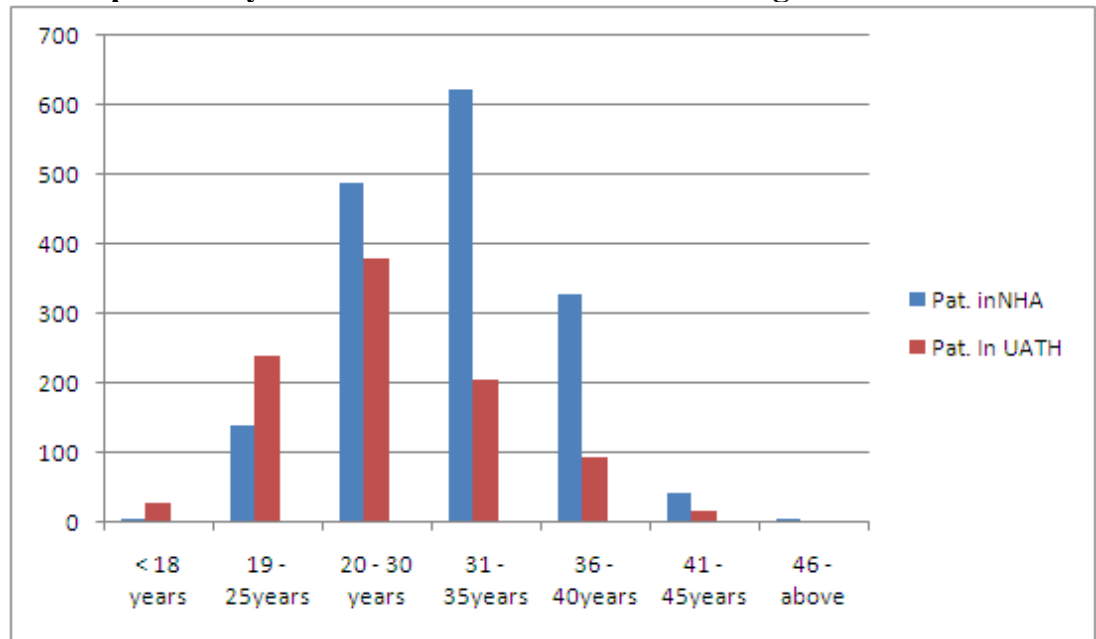

Table 5 showing party distribution of $\mathrm{C} / \mathrm{S}$ patients

\begin{tabular}{|l|l|l|l|l|l|}
\hline S/N & PARITY & $\begin{array}{l}\text { FREQUENCY IN } \\
\text { NHA }\end{array}$ & $\%$ & $\begin{array}{l}\text { FREQUENCY IN } \\
\text { UATH }\end{array}$ & \% \\
\hline 1 & Para 0 & 516 & 31.8 & 416 & 43.6 \\
\hline 2 & Para 1 & 438 & 27.0 & 224 & 22.9 \\
\hline 3 & Para 2 & 348 & 21.49 & 146 & 14.9 \\
\hline 4 & Para 3 & 173 & 10.68 & 66 & 6.76 \\
\hline 5 & Para 4 & 96 & 5.92 & 59 & 6.0 \\
\hline 6 & Para 5 & 31 & 1.91 & 19 & 1.9 \\
\hline 7 & Para 6 & 9 & 0.55 & 26 & 2.6 \\
\hline 8 & Para 7 & 4 & 0.24 & 2 & 0.2 \\
\hline 9 & Para 8 & 3 & 0.18 & 2 & 0.2 \\
\hline 10 & Para 9 & 1 & 0.06 & 0 & - \\
\hline 11 & Para 10 & - & 0 & 1 & 0.1 \\
\hline
\end{tabular}

Source: $O$ and G records, NHA \& UATH 2011 \& 2012.

Figure 3 Showing Frequency Distribution of Parity in NHA \& UATH

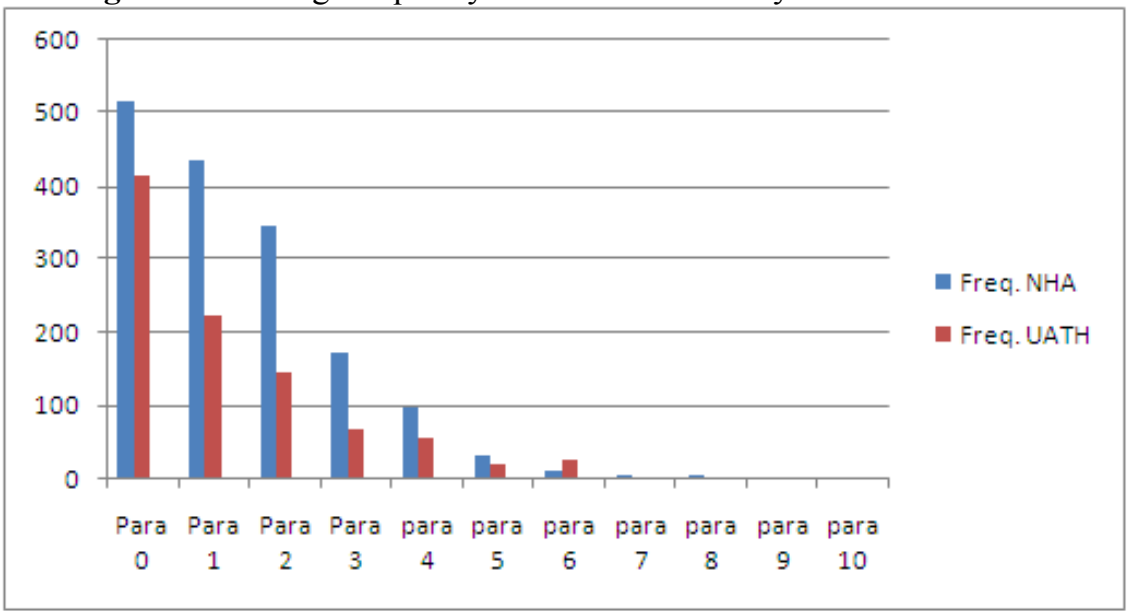

The title reveals that in the case study, primigravidae constituted the majority of the patients who had CS (31.8\% and 43.6\%) in NHA and UATH respectively. This is followed by secundigravidae cases. The rate of $\mathrm{CS}$ reduces downward as parity increases. The cases in primigravidae are more because they following reasons: 
a) It is their first delivery and thus their labour period is longer.(12-18hours)

b) Prone to medical disease like pre-eclampsia.

It is noted that the more the number of parity the lesser the number of CS frequency.

Question 4 : What are the factors and indices that influence Caesarean section?

The researcher has been able to establish the following factors influencing CS in the case study.

a) The medical factor which deals most with the indications as already described elsewhere in this article.

b) Age: patients that are under 18 years do not have fully developed pelvis and therefore prone to more CS.

c) Financial capability/prestige. The CS is relatively more costly than normal delivery. The table below shows the cost rate in the case study.

Table 6-showing the cost rate for CS and normal Delivery

\begin{tabular}{|l|l|l|l|}
\hline S/N & HOSPITAL & $\begin{array}{l}\text { RATE OF NORMAL } \\
\text { DELIVERY }\end{array}$ & RATE OF CS DELIVERY \\
\hline 1 & National Hospital Abuja & $\$ 35,000$ per rate & $\begin{array}{l}\$ 95,000=\text { for booked } \\
1135,000=\text { unbooked }\end{array}$ \\
\hline 2 & University of Abuja Teaching Hospital & $\$ 6,000$ per rate & $\$ 60,000=$ unbooked \\
\hline
\end{tabular}

Source: NHA \& UATH

The rate revealed that normal delivery and CS are more in NHA than UATH; therefore, prestige takes more of the reasons for CS because NHA is more central and it is regarded as premier hospital in Nigeria.

d) Late Child Delivery: Though we did not have many of these cases in both hospitals. It has been discovered that those with late Child bearing mostly undergo CS for their safety and that of the babies.

e) Emergencies: This is one of the reasons that influence CS even without booking or payment of deposit can be done to save the life of the patient first.

Question 5: How Adequate are CS and how many types of CS do we have?

Table 7 is showing status and types of Caesarian Section.

\begin{tabular}{|l|l|l|l|l|l|}
\hline S/N & HOSPITAL & $\begin{array}{l}\text { BOOKED } \\
\text { STATUS }\end{array}$ & EMERGENCY CS & ELECTIVE CS & TOTAL \\
\hline 1 & National Hospital Abuja & $\begin{array}{l}\text { Booked } \\
\text { Unbooked }\end{array}$ & 440 & $708=1,148$ & 634 \\
& & 240 & $58=692$ & 1,074 \\
\hline 2 & University of Abuja & Booked & 200 & $700=1,840$ \\
& Teaching Hospital & Unbooked & $500=740$ & $300=500$ & 440 \\
\end{tabular}

Source: NHA \& UATH 2011 \& 2012

The cases of emergency from the table are more than the elective. From the table above the following can be seen.

a) Total number of emergency CS $=1,888 \quad 220.68^{0}$

b) Total number of Elective CS $=1,192139.32^{\circ}$

\section{$3,080360^{\circ}$}

The distributions of Emergency to Elective CS are shown in the pie chart below.

Figure 3 showing the type of CS

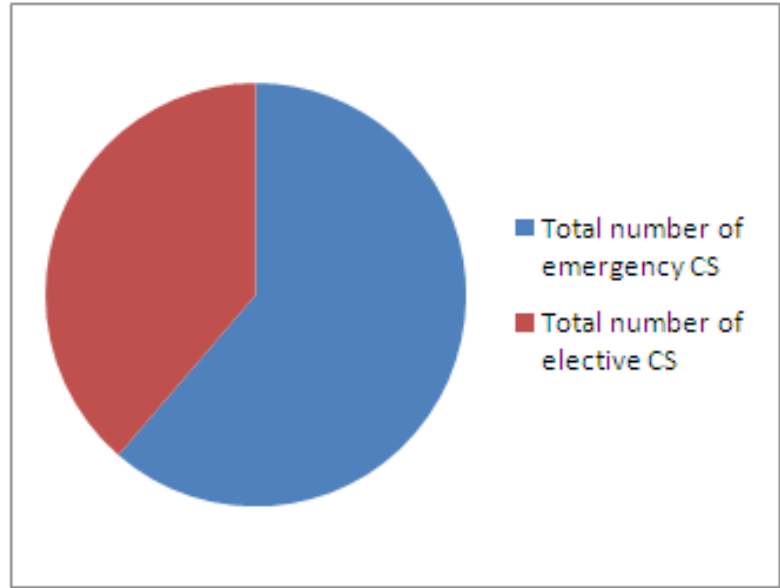

The adequacy of Caesarean section is governed by the following indices.

a) The quantity or rate of anaesthesia used 
b) The prevention of risk factors

c) The safety and preservation of life of the mother and baby

d) Handling of post-delivery complication

e) Less mortality rate after CS

f) The skill and expertise of the surgeon as well as the materials used.

Evaluation of the Caesarean sections in the case study has revealed less mortality and morbidity, most of the surgeons are renowned and experienced consultants with many resident Doctors. There are enough and good specialized facilities that measure the anaesthetic used.

\section{Discussion}

The research presents a survey of the factors that influence Caesarean section in Tertiary Hospitals in the F.C.T. There are two tertiary hospitals. The population used shows that the factors that influence Caesarean section are medical, physical, social, psychological and environmental in nature.

The medical factors which are mostly indications are classified into maternal, foetal and feto-maternal causes. The maternal causes are more of the indications with about $57 \%$. This is followed by foetal causes with $30 \%$ and feto-maternal with $13 \%$. Other factors that influence Caesarean Section are age of patients, the location of the hospital, prestige and financial capability, late child delivery as well as emergencies. Encounter with patients show that majority of the Caesarean sections is within the 'primigravidae age' than any other Para group.

$\mathrm{O}$ and $\mathrm{G}$ nurses and the Obstetricians and Gynaecologists agreed that majority of the Caesarean sections are emergencies gravitated by medical reasons in order to save the lives of the patients and babies.

Even though financial ability plays a vital role, it has been found that the hospitals at the suburb operate more of emergency cases that are not booked than the ones in the city. They receive more of referral cases than National Hospital. National Hospital is more organized, central, more sophisticated as a premier health centre, and therefore more patients prefer Caesarean section in it because they feel more secure and this gives them prestige.

\section{Limitations}

This study has some limitations which include reaching out to the respondents, selection of patients and their unwillingness to speak sometimes. No demographic data on birth rate is readily available, and therefore, the results may not be completely free from bias which constituted a limitation. The study considered the factors that influenced Caesarean section which are medical, social or physiological based on the individual involved.

\section{Conclusion}

Caesarean section is one of the methods of child delivery which is usually explored either by the choice of the patients, medical constraints, protracted labour or by emergency. It is obviously costly in the city centre and the safest and quickest means of child delivery to avoid any form of complications. The study recommended the need to explore the normal delivery at first delivery so as to reduce the number of C.S after the first child

\section{Acknowledgement}

This is to acknowledge the persons whose contributions made this research a success. First I acknowledge the Almighty God for His ever enduring help and succour. My utmost gratitude goes to my husband Mr. Oyewole and also Dr. Yayok P. K; my Head of Department Mallam Umar Aliyu Mayo for their unrelenting efforts in encouraging and reviewing the scripts. Many thanks to the members of my unit, department and National Hospital Abuja.

\section{Reference}

[1]. Chassar Moir J.'s Caesarean Section, Sterilization, Hysterectomy. In Munro Kerr's Operative Obstetrics; Balliere Tindall and Cux, London, 1956

[2]. Ahmed ETS, Mirghani OA et al Cethiaxone vs Ampicillincloxacillin as antibiotic prophylaxis in elective C.S; Eastern Mediterranean Journal, 2004.

[3]. Johanson R.'s Malposition, Malpresentations and Cepholopelvic Disproportion. In: Dewhurst's Textbook of Obstetrics and Gynaecology for Post graduates, 6 th $_{\text {th }}$ Edition. D.K. Edmonds Ed: Blackwell Science Ltd., Oxford, 1999; 288-289.

[4]. Orosanye A.U, Diejemoah F.M.E, Omone J.A: A review of Caesarean Section at University of Benin Teaching Hospital, Benin City, Nigeria, 1973- 1976. In Ojo O.A, Aimakhu V.E, Akinla O., Emmanuel L.A, Chukwubedelu W.O (ed)- Obstetrics and Gynaecology in Developing Countries, 1977; $402-409$.

[5]. Otubu J.A.M, Caesarean Section; In Agboola's: Textbook of Obstetrics and Gynaecology for medical students. Volume 2, University Services Educational Publishers Ltd., Lagos, 1988; 218-231.

[6]. Igberese G.O, Ebeigbe P.N, Andrew B.O: High Caesarean Section Rate, a 10 year experience in a Tertiary Hospital in Niger Delta, Nigeria; J. Clinic Practice, 2009.

[7]. Ezechi O.C, Nwokoro C.A, Kalu BKE et al Caesarean Morbidity and Mortality in a Private Hospital in Lagos, Nigeria, 2002. 
[8]. Umoh A.V, Abah G.M, Eta O.A: A study of Caesarean Sectors in Secondary Health Facility in Uyo, South Nigeria, Abstract from WACS, 2010.

[9]. Efetie E.E- A review of Caesarean Section in National Hospital, Abuja (September 1999 to September 2001). A part 2 fellowship dissertation submitted to the West African College of Surgeons, Faculty of Obstetrics and Gynaecology, April, 2002.

[10]. Kwawukume E.Y, Caesarean Section; In: Comprehensive Obstetrics in the Tropics (Ed. E.Y Kwawukume, E. Ejiro Emuveyan). Asante and Hittscher Printing Press, Dansoman, 2002; Page 321 - 329.

[11]. Jaiyesimi and Ojo OE, Csin Okonofua F. Odunsi (eds)- Contemporary Obstetrics and Gynaecology for Developing Countries, Benin WHARC, 2003.

[12]. Briggs N.D's Illiteracy and Maternal Health, Education or Die, Lancet, 1993.

[13]. Okafor C.I, Onwusulu D.N: Rising Caesarean Section Rates; Any hope of Decline?. The NAUTH Nnewi Exp., 2000.

[14]. Nwokocha F.N: Overview of Obstetric Caesarean Section in National Hospital, Abuja (Medical Lecture).

[15]. Yayok P.K: Factors influencing Population Distribution in F.C.T for the purpose of securing adequate housing. Paper submitted at Post-doctoral studies of MUST University, U.S.A, 2013.

[16]. SURE-P PHC; The infant mortality rate and means of addressing them. Survey in F.C.T, Abuja, 2014.

[17]. Tranquilli A.L and Garzetti G.G: A new ethical and clinical dilemma in Obstetrics Practice; Caesarean Section on maternal request. American J. of Obstetrics and Gynaecology, 1997; 177: 245-246.

[18]. Jackson N.V an Irvine L.M: The influence of maternal request on the elective Caesarean Section rate. Journal of Obstetrics and Gynaecology, 1998; 18: 115-119.

\section{Tables}

$\overline{\text { Table } 1}$ - Showing patients that registered for antenatal clinics.

Table 2 - Showing Booked \& Unbooked Patients.

Table 3 - Showing indication Causes for Caesarean Sections in tertiary hospitals.

Table 4- Showing age range of Patients with CS.

Table 5 - Showing Parity Distribution of CS patients;

Table 6 - Showing Cost rates for CS \& Normal Deliveries in Hospitals

Table 7 - Showing booking Status and types of CS

\section{FIGURES}

Figure 1- Pie Chart Showing Booked \& Unbooked patients

Figure 2 - Bar Chart showing age distribution of patients

Figure 3 - Bar Chart showing Parity Distribution of CS Patients.

Abbreviations

\begin{tabular}{|l|l|l|}
\hline 1 & PET & Pre-eclampsia Toxemia \\
\hline 2 & PMTCT & Prevention of Mother to Child Transmission \\
\hline 3 & IVF Pregnancy & Intra Vitro fertilization \\
\hline 4 & BOH & Bad Obstetric History \\
\hline 5 & IUGR & Intra-Uterine Growth Retardation \\
\hline 6 & PROM & Premature Rupture of membrane \\
\hline 7 & IOL & Induction Of Labour \\
\hline 8 & IUFD & Intra Uterine Foetal Death \\
\hline 9 & PIH & Pregnancy Induced Hypertensive \\
\hline 10 & SCD & Sickle Cell Disease \\
\hline 11 & CA & Cancer \\
\hline 12 & CS & Caesarean Section \\
\hline 13 & UATH & University of Abuja Teaching Hospital \\
\hline 14 & NHA & National Hospital Abuja \\
\hline 15 & FCT & Federal Capital Territory \\
\hline
\end{tabular}

